\title{
Methylglyoxal-Scavenging Enzyme Activities Trigger Erythroascorbate Peroxidase and Cytochrome c Peroxidase in Glutathione-Depleted Candida albicans
}

\author{
Sa-Ouk Kang ${ }^{1 *}$ and Min-Kyu Kwak ${ }^{2 *}$ \\ 'Laboratory of Biophysics, School of Biological Sciences, and Institute of Microbiology, Seoul National University, \\ Seoul 08826, Republic of Korea \\ ${ }^{2}$ Department of Food and Nutrition, Institute of Food and Nutrition Science, Eulji University, Seongnam 13135, \\ Republic of Korea
}

\begin{abstract}
$\gamma$-Glutamylcysteine synthetase (Gcs1) and glutathione reductase (GIr1) activity maintains minimal levels of cellular methylglyoxal in Candida albicans. In glutathione-depleted $\Delta$ gcs 1 , we previously saw that NAD(H)-linked methylglyoxal oxidoreductase (Mgd1) and alcohol dehydrogenase (Adh1) are the most active methylglyoxal scavengers. With methylglyoxal accumulation, disruptants lacking MGD1 or $A D H 1$ exhibit a poor redox state. However, there is little convincing evidence for a reciprocal relationship between methylglyoxal scavenger genes-disrupted mutants and changes in glutathione-(in)dependent redox regulation. Herein, we attempt to demonstrate a functional role for methylglyoxal scavengers, modeled on a triple disruptant ( $\Delta \operatorname{mgd} 1 / \Delta a d h 1 / \Delta g c s 1)$, to link between antioxidative enzyme activities and their metabolites in glutathione-depleted conditions. Despite seeing elevated methylglyoxal in all of the disruptants, the result saw a decrease in pyruvate content in $\Delta m g d 1 / \Delta a d h 1 / \Delta g c s 1$ which was not observed in double gene-disrupted strains such as $\Delta m g d 1 / \Delta g c s 1$ and $\Delta a d h 1 / \Delta g c s 1$. Interestingly, $\Delta m g d 1 / \Delta a d h 1 / \Delta g c s 1$ exhibited a significantly decrease in $\mathrm{H}_{2} \mathrm{O}_{2}$ and superoxide which was also unobserved in $\Delta m g d 1 / \Delta g c s 1$ and $\Delta a d h 1 / \Delta g c s 1$. The activities of the antioxidative enzymes erythroascorbate peroxidase and cytochrome $c$ peroxidase were noticeably higher in $\Delta m g d 1 / \Delta a d h 1 / \Delta g c s 1$ than in the other disruptants. Meanwhile, GIr 1 activity severely diminished in $\Delta m g d 1 / \Delta a d h 1 / \Delta g c s 1$. Monitoring complementary gene transcripts between double gene-disrupted $\Delta m g d 1 / \Delta g c s 1$ and $\Delta a d h 1 / \Delta g c s 1$ supported the concept of an unbalanced redox state independent of the GIr1 activity for $\Delta m g d 1 / \Delta a d h 1 / \Delta g c s 1$. Our data demonstrate the reciprocal use of Eapx 1 and Ccp 1 in the absence of both methylglyoxal scavengers; that being pivotal for viability in non-filamentous budding yeast.
\end{abstract}

Received: October 28, 2020 Accepted: November 13, 2020

First published online November 16,2020

*Corresponding authors S-O.Kang

Phone: +82-2-880-6703 Fax: +82-2-888-4911

E-mail: kangsaou@snu.ac.kr M-K.Kwak

Phone: +82-31-740-7418

Fax: $+82-31-740-7370$

E-mail: genie6@eulji.ac.kr

pISSN 1017-7825

elSSN 1738-8872

Copyright(C) 2021 by

The Korean Society for

Microbiology and

Biotechnology
Keywords: Alcohol dehydrogenase 1, Candida albicans, erythroascorbate peroxidase, glutathione, methylglyoxal, $\mathrm{NAD}(\mathrm{H})$-linked methylglyoxal oxidoreductase

\section{Introduction}

Methylglyoxal ( $\mathrm{MG}, \mathrm{CH}_{3} \mathrm{COCHO}$ ) reacts with nucleic acids and proteins, causing to cellular damage [1], and also inhibits cell division in eukaryotes [2]. MG non-specifically binds to amines, amino acids, and proteins and produces biologically active free radicals [3-5]. Advanced glycation end-products are derived from MG, leading to hyperglycemic damage in cells $[1,6]$. This highly reactive a-ketoaldehyde inhibits human leukemia 60 cells, resulting in apoptosis [7]. In the fission yeast Schizosaccharomyces pombe, MG can activate stress-activated protein kinase signaling cascade [8].

As demonstrated in our previous studies at the microbial level, MG accumulation in cells results in the defective growth and the arrest of the G1-phase specific cell cycle in $\gamma$-glutamyl cysteinyl synthetase (GCS)-deficient $g c s^{-}$of Dictyostelium discoideum [9]. Glutathione (GSH)-depleted strains provide a working concept for cellular accumulation of MG via the inactive GSH-required glyoxalase system [9]. Investigations have focused on a number of MG scavengers, including aldehyde dehydrogenase, aldehyde reductase, aldose reductase, and $\alpha$ ketoaldehyde dehydrogenase. These enzymes commonly catalyze the oxidation or reduction of MG into pyruvate or acetol [10]. Inspired by these findings, in Candida albicans, we previously purified and characterized two predominant MG-scavenging enzymes, NAD $(\mathrm{H})$-linked alcohol dehydrogenase 1 (CaO19.3997; Adh1) [11] and NAD(H)-linked MG oxidoreductase (CaO19.4309; Mgd1) [12]. The Mgd protein, Mgd1, has been revealed to be 
CaO19.4309 of C. albicans SC5314 Assembly 22 [12]. This oxidoreductase was a glycine-rich protein (Grp2) associated with the Gre2 family likely as a putative NAD(P)H-dependent MG reductase (http://www. candidagenome.org/). The revealed common mechanism of activities of these enzymes is that Mgd1 and Adh1 activities catalyze the oxidation and reduction of MG to pyruvate and acetol, respectively. Disruption of the genes encoding $\mathrm{NAD}(\mathrm{H})$-linked Mgd1 and Adh1 leads to defects in cell growth, differentiation, and G1-phase cell-cycle arrest, accompanied by accumulations of MG and pyruvate with mitochondrial inactivity [11]. ADH1 disruptants, constructed of both the wild-type and GSH-depleted $\Delta g c s 1$ (C. albicans GCS1), display supraphysiological increase in MG, as well as severe defects in growth, differentiation, and full virulence. Interestingly, Mgd1 activity scavenges both MG and pyruvate to maintain metabolic homeostasis and redox buffers via the triggering of a combination of glycolytic enzymes and Adh 1 expression.

However, there is little data concerning cellular MG content-dependent oxidative stress-responsive enzyme activity alteration in C. albicans [12]. Reactive oxygen species (ROS) are formed from the reduction of one or two electrons of molecular oxygen creating hydroxyl radicals $\left({ }^{\circ} \mathrm{OH}\right)$, superoxide anions $\left(\mathrm{O}_{2}{ }^{-}\right)$, and hydrogen peroxide $\left(\mathrm{H}_{2} \mathrm{O}_{2}\right)$ [13]; all being causative factors in DNA mutations and genomic instability [14]. Although convincing evidence for MG-triggered ROS production and/or ROS-mediated MG content control is lacking, the scavenging mechanisms of ROS have been sufficiently elucidated; the superoxide anions scavenged by superoxide dismutases (Sods) generate the simplest form of peroxide, $\mathrm{H}_{2} \mathrm{O}_{2}$, which is detoxified by catalase (Cat) and/or GSH reductase (GR) $[15,16]$. ROS, antioxidative enzyme activities, and their resulting metabolite products have been postulated. Studies on redox regulatory mechanisms have linked them to cell growth, proliferation, division, and differentiation in eukaryotic microorganisms [13] including C. albicans $[11,12,17,18]$. Partial experimental data concerning cellular MG-derived ROS generation, in the absence of the antioxidative activities of several enzymes, comes from previously observed MG and ROS accumulations, with resulting defects in growth, filamentation, and virulence $[12,19,20]$. These include erythroascorbate peroxidase (CaO19.584, Eapx1) [19], cytochrome $c$ peroxidase (CaO19.7868, Ccp1) [20], Gcs1 (CaO19.5059) [21], and Glr1 (CaO19.4147) [18]. However, at present there is little data regarding the effects of the absence of the MG scavengers Mgd1 and Adh1 in GSH-depleted states on the production of ROS, or the resulting physiology during proliferation. In this study, using experiments based on GSH-depleted non-hyphae-inducing cells independent of GSH metabolism, we examine the cellular MG-derived enhanced antioxidative enzyme activities resulting from a lack of representative MG scavengers using the triple disruptant $\Delta m g d 1 / \Delta a d h 1 / \Delta g c s 1$. Thus, using measurements of redox metabolites and MG, we demonstrate how antioxidative actions by $C$. albicans enzymes contribute to redox regulation.

\section{Materials and Methods}

\section{Strains and Growth Conditions}

The C. albicans strains used in this study are listed in Table 1. To culture C. albicans cells harboring disrupted genes, $\mathrm{Ura}^{+}$and $\mathrm{Ura}^{-}$strains were cultured in minimally defined SD and YPD media [21], respectively. YPD medium ( $1 \%$ yeast extract, $2 \%$ peptone, $2 \%$ glucose) or minimally defined SD ( $2 \%$ glucose, $0.5 \%$ ammonium sulfate, $0.17 \%$ yeast nitrogen base without amino acids and ammonium sulfate) medium and appropriate supplements in liquid broth or $1.8 \%$ agar-containing plates were prepared and utilized by means described previously [22]. Unless otherwise stated, all physiological and biochemical experiments employed $\mathrm{Ura}^{+}$ heterozygous strains. All Ura ${ }^{+}$-strains were commonly grown in SD broth and inoculated at an optical density of $1 \times 10^{6}$ cells $/ \mathrm{ml}$ at $28^{\circ} \mathrm{C}[22]$. GSH depletion from the Ura ${ }^{+}$GCS1 disruptant and its derivatives was performed using previously detailed methods $[9,21]$.

\section{$A D H 1$ and MGD1 Disruption}

$M G D 1$ and $A D H 1$ disruption was conducted in $\triangle g c s 1$ using known means $[11,12]$. An $M G D 1$ and $A D H 1$ triple disruptant derived from the MK604 ( $\Delta m g d 1 / \Delta g c s 1)$ strain was constructed to create MK803 ( $\Delta m g d 1 / \Delta a d h 1 /$ $\Delta g c s 1)$. Both genes were commonly disrupted using the URA blaster method employing pQF181 and its derivative pQF182 to remove the MGD1- and ADH1-coding regions, respectively [23-25]. The primers and plasmids used in this study are detailed in Table 1. Using YB204, a homozygous Ura $\Delta g c s 1$, spontaneous Ura $^{+}$strains from

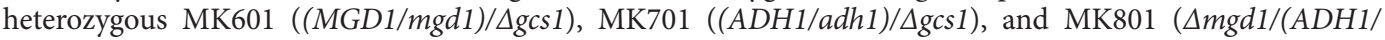
adh1)/Agcs1) disruptants were selected on SD plates supplemented with 5-fluoroorotic acid to reveal the URA3 locus using uracil prototrophy [25]. The resulting homozygous MK602 ((MGD1/mgd1)/ $\operatorname{gcs} 1)$, MK702 ((ADH1/ $a d h 1) / \Delta g c s 1)$, and MK802 ( $\Delta m g d 1 /(A D H 1 / a d h 1) / \Delta g c s 1)$ strains were confirmed to contain disrupted $A D H 1$ or $M G D 1$, and to have lost the URA3 gene, through intrachromosomal recombination between tandem $h p h$ repeats. Using the same method described above, spontaneous recombination between the $h p h$ repeats involved selection on FOA plates and utilization for a second round of transformations. Ura ${ }^{+}$transformants were then selected on uracil-deficient media, yielding MK603 ( $\Delta m g d 1 / \Delta g c s 1)$, MK703 ( $\Delta a d h 1 / \Delta g c s 1)$, and MK803 ( $\Delta m g d 1 / \Delta a d h 1 /$ $\Delta g c s 1)$. Unless otherwise stated, all the physiological and biochemical experiments were performed using Ura ${ }^{+}$ heterozygous strains (i.e., YB203, $\Delta$ gcs 1; MK603, $\Delta m g d 1 / \Delta g c s 1 ;$ MK703, $\Delta a d h 1 / \Delta g c s 1 ;$ MK803, $\Delta m g d 1 / \Delta a d h 1 /$ $\Delta g c s 1)$

\section{Quantification of Quinoxaline Derivatives}

MG and pyruvate levels were measured by converting these metabolites into quinoxaline derivatives using 1,2diaminobenzene (Merck) and methods already detailed $[9,26]$. For utilization in enzymatic studies and intracellular quantification, MG from a commercial $40 \%$ solution was repurified by vacuum distillation (Sigma, 
Table 1. Strains, primers, and plasmids used in this study.

\begin{tabular}{|c|c|c|}
\hline $\begin{array}{l}\text { Strain, primer, } \\
\text { or plasmid }\end{array}$ & Genotype, sequence, or description & $\begin{array}{l}\text { Source or } \\
\text { reference }\end{array}$ \\
\hline \multicolumn{3}{|l|}{ C. albicans } \\
\hline SC5314 & Wild type isolate & $\begin{array}{l}\text { Fonzi and Irwin, } \\
1993\end{array}$ \\
\hline CAI4 & 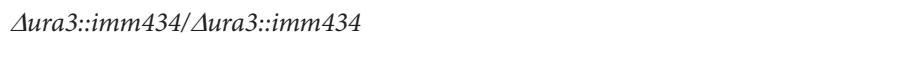 & $\begin{array}{l}\text { Fonzi and Irwin, } \\
1993\end{array}$ \\
\hline $\begin{array}{l}\text { YB203, heterozygous } \\
\Delta g c s 1\end{array}$ & 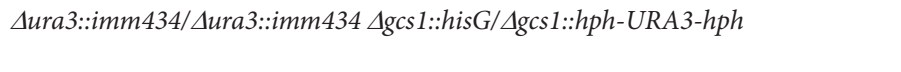 & Baek et al., 2004 \\
\hline $\begin{array}{l}\text { YB204, homozygous } \\
\Delta g c s 1\end{array}$ & 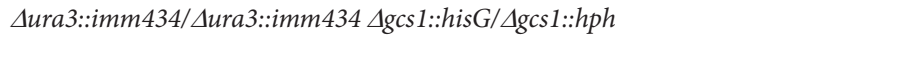 & Baek et al., 2004 \\
\hline $\begin{array}{l}\text { MK601, heterozygous } \\
(M G D 1 / m g d 1) / \Delta g c s 1\end{array}$ & As YB204, but $\Delta u r a 3:: i m m 434 / \Delta u r a 3:: i m m 434 \Delta m g d 1:: h p h-U R A 3-h p h / M G D 1$ & Kwak et al., 2018 \\
\hline $\begin{array}{l}\text { MK602, homozygous } \\
(M G D 1 / m g d 1) / \Delta g c s 1\end{array}$ & As YB204, but $\Delta u r a 3:: i m m 434 / \Delta u r a 3:: i m m 434 \Delta m g d 1:: h p h / M G D 1$ & Kwak et al., 2018 \\
\hline $\begin{array}{l}\text { MK603, heterozygous } \\
\Delta m g d 1 / \Delta g c s 1\end{array}$ & $\begin{array}{l}\text { As YB204, but } \Delta u r a 3:: i m m 434 / \Delta u r a 3:: i m m 434 \Delta m g d 1:: h p h / \Delta m g d 1:: h p h-U R A 3- \\
h p h\end{array}$ & Kwak et al., 2018 \\
\hline $\begin{array}{l}\text { MK604, homozygous } \\
\Delta m g d 1 / \Delta g c s 1\end{array}$ & As YB204, but $\Delta u r a 3:: i m m 434 / \Delta u r a 3:: i m m 434 \Delta m g d 1:: h p h / \Delta m g d 1:: h p h$ & Kwak et al., 2018 \\
\hline $\begin{array}{l}\text { MK701, heterozygous } \\
(A D H 1 / a d h 1) / \Delta g c s 1\end{array}$ & As YB204, but $\Delta a d h 1:: h p h-U R A 3-h p h / A D H 1$ & Kwak et al., 2014 \\
\hline $\begin{array}{l}\text { MK702, homozygous } \\
(\text { ADH1/adh1)/ } \operatorname{gcs} 1\end{array}$ & As YB204, but $\Delta a d h 1:: h p h / A D H 1$ & Kwak et al., 2014 \\
\hline $\begin{array}{l}\text { MK703, heterozygous } \\
\Delta a d h 1 / \Delta g c s 1\end{array}$ & As YB204, but $\Delta a d h 1:: h p h / \Delta a d h 1:: h p h-U R A 3-h p h$ & Kwak et al., 2014 \\
\hline $\begin{array}{l}\text { MK704, homozygous } \\
\Delta a d h 1 / \Delta g c s 1\end{array}$ & As YB204, but $\Delta a d h 1:: h p h / \Delta a d h 1:: h p h$ & Kwak et al., 2014 \\
\hline $\begin{array}{l}\text { MK801, heterozygous } \\
\Delta m g d 1 /(A D H 1 / \\
\text { adh1)/ } \operatorname{ccs} 1\end{array}$ & As MK604, but $\Delta u r a 3:: i m m 434 / \Delta u r a 3:: i m m 434 \Delta a d h 1:: h p h-U R A 3-h p h / A D H 1$ & Kwak et al., 2018 \\
\hline $\begin{array}{l}\text { MK802, homozygous } \\
\Delta m g d 1 /(A D H 1 / \\
a d h 1) / \Delta g c s 1\end{array}$ & 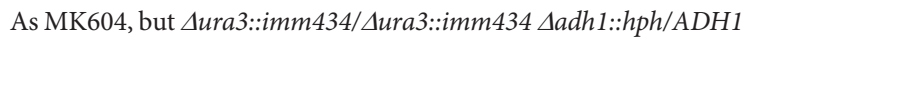 & Kwak et al., 2018 \\
\hline $\begin{array}{l}\text { MK803, heterozygous } \\
\Delta m g d 1 / \Delta a d h 1 / \Delta g c s 1\end{array}$ & $\begin{array}{l}\text { As MK604, but } \Delta u r a 3:: i m m 434 / \Delta u r a 3:: i m m 434 \Delta a d h 1:: h p h / \Delta a d h 1:: h p h-U R A 3- \\
\text { hph }\end{array}$ & Kwak et al., 2018 \\
\hline $\begin{array}{l}\text { MK804, homozygous } \\
\Delta m g d 1 / \Delta a d h 1 / \Delta g c s 1\end{array}$ & As MK604, but $\Delta u r a 3:: i m m 434 / \Delta u r a 3:: i m m 434 \Delta a d h 1:: h p h / \Delta a d h 1:: h p h$ & Kwak et al., 2018 \\
\hline \multicolumn{3}{|l|}{ Primers } \\
\hline MK1a-SacI & 5'-GAGCTCGGATAACTCTTCGTTTTATCCGTC-3', SacI site of pMK1F & Kwak et al., 2018 \\
\hline MK1b-KpnI & 5'-GGTACCATATGAAGATATTTTTTAATTGAT-3', KpnI site of pMK1F & Kwak et al., 2018 \\
\hline MK1c-SalI & 5'-GTCGACATGATATTCAGATTGAATGATGAT-3', SalI site of pMK1R & Kwak et al., 2018 \\
\hline MK1d-HindIII & 5'-AAGCTTATATTTGATCGCGAAGCAGATGTC-3', HindIII site of pMK1R & Kwak et al., 2018 \\
\hline MK2a-SacI & 5'-GAGCTCTTACAATATTTGATAGAGACCCAA-3', SacI site of pMK2F & Kwak et al., 2014 \\
\hline MK2b-KpnI & 5'-GGTACCAAGTGCGGGATTATCCTTTTTGAG-3', KpnI site of pMK2F & Kwak et al., 2014 \\
\hline MK2c-SalI & 5'-GTCGACAAATAGCTAAATTATATACGAATT-3', SalI site of pMK2R & Kwak et al., 2014 \\
\hline MK2d-HindIII & 5'-AAGCTTAAACTTGAAAACACCGAGTTGATA-3', HindIII site of pMK2R & Kwak et al., 2014 \\
\hline \multicolumn{3}{|l|}{ Plasmids } \\
\hline pQF181 & pUC18 containing $h p h$-URA3- $h p h$ (forward) from pQF86 & Kwak et al., 2018 \\
\hline pQF182 & pUC18 containing $h p h$-URA3-hph (reverse) from pQF86 & Kwak et al., 2018 \\
\hline pMK1F & $\begin{array}{l}\text { pGEM-T Easy vector containing MK1a-MK1b fragment, upstream region of } \\
\text { MGD1 }\end{array}$ & Kwak et al., 2018 \\
\hline pMK1R & $\begin{array}{l}\text { pGEM-T Easy vector containing MK1c-MK1d fragment, downstream region of } \\
\text { MGD1 }\end{array}$ & Kwak et al., 2018 \\
\hline pMK2F & MGD1 deletion construct with $h p h-U R A 3-h p h$ (forward) & Kwak et al., 2018 \\
\hline pMK2R & MGD1 deletion construct with $h p h-U R A 3-h p h$ (reverse) & Kwak et al., 2018 \\
\hline pMK3F & pGEM-T Easy vector containing MK2a-MK2b, upstream region of $A D H 1$ & Kwak et al., 2014 \\
\hline pMK3R & pGEM-T Easy vector containing MK2c-MK2d, downstream region of $A D H 1$ & Kwak et al., 2014 \\
\hline pMK4F & $A D H 1$ deletion construct with $h p h-U R A 3-h p h$ (forward) & Kwak et al., 2014 \\
\hline pMK4R & ADH1 deletion construct with $h p h$-URA3-hph (reverse) & Kwak et al., 2014 \\
\hline
\end{tabular}

USA) to eliminate polymerized MG and impurities [27]. The distilled MG concentration was calculated to be $0.5565 \mathrm{M}$, which was stoichiometrically confirmed by 2-methylquinoxaline (Sigma) using a high-performance liquid chromatography (HPLC) system. Analytical grade pyruvate (Sigma) was purchased and used without further purification. Quinoxaline derivatives of MG and pyruvate (i.e., 2-methylquinoxaline and 2-hydroxy-3- 
methylquinoxaline) were obtained using a solid-phase extraction (SPE) cartridge (Waters) containing a C18 resin. The resulting derivatives were separated using an Agilent 1200 series HPLC system with a Zorbax Eclipse XDBC18 analytic column (Agilent, $150 \times 4.6 \mathrm{~mm}$ ) at a wavelength of $336 \mathrm{~nm}$ with an internal standard 5methylquinoxaline (Sigma).

\section{D-Erythroascorbic Acid and GSH Measurements}

The intracellular D-erythroascorbic acid content was measured by employing known techniques [28, 29]. Samples were applied to an analytical HPLC system (Waters) that was equipped with a Waters 460 electrochemical detector. The resulting extracts were separated with ZORBAX SB-C18 columns (Agilent, $250 \mathrm{~mm} \times 4.6 \mathrm{~mm}$ ) and eluted with $0.1 \%$ trifluoroacetic acid at a flow rate of $0.7 \mathrm{ml} / \mathrm{min}$.

Cellular GSH was labeled with monobromobimane $(\mathrm{mBBr})$ and measured as described previously [30]. The $\mathrm{mBBr}$-derivatized thiol compounds were analyzed by HPLC with a Hewlett-Packard 1050 series fluorescence detector with ZORBAX SB-C18 columns (Agilent, $250 \mathrm{~mm} \times 4.6 \mathrm{~mm}$ ). Samples were eluted with $0.1 \%$ trifluoroacetic acid at a flow rate of $0.7 \mathrm{ml} / \mathrm{min}$. The mobile phase consisted of $15 \%$ methanol and $85 \%$ trifluoroacetic acid $(0.1 \%)$ at a wavelength at $370 \mathrm{~nm}$.

\section{Superoxide and $\mathrm{H}_{2} \mathrm{O}_{2}$ Measurements}

C. albicans cells grown in liquid SD medium until the early $(12 \mathrm{~h})$ and late $(24 \mathrm{~h})$ exponential phases of cell growth were harvested, washed, and resuspended at $10^{8}$ cells $/ \mathrm{ml}$ in $100 \mathrm{mM}$ sodium phosphate buffer ( $\mathrm{pH}$ 6). The intracellular superoxide content was measured using dihydroethidium with $18.9 \mu \mathrm{M}$ dihydroethidine [31]. Superoxide anions were measured using a Cary Eclipse fluorescence spectrophotometer (Varian) with $\lambda \mathrm{ex}=$ $518 \mathrm{~nm}, \lambda \mathrm{em}=605 \mathrm{~nm}$.

Cellular peroxide was estimated using $19.5 \mu \mathrm{M} 2^{\prime}, 7^{\prime}$-dichlorofluoroscein diacetate $\left(\mathrm{H}_{2} \mathrm{DCFDA}\right)$ with a Cary Eclipse fluorescence spectrophotometer (Varian) with $\lambda$ ex $=495 \mathrm{~nm}$ and $\lambda \mathrm{em}=525 \mathrm{~nm}$, with previously described methods [12].

\section{Enzyme Activity Assays}

Cells were grown in minimally defined SD medium until the early $(12 \mathrm{~h})$ and late $(24 \mathrm{~h})$ exponential phases, harvested by centrifugation at 6,000 $\mathrm{g}$ for $15 \mathrm{~min}$, and then homogenized using a Mini Bead-Beater (Biospec Products) for $90 \mathrm{~s}$ containing $1 \mathrm{mM}$ phenylmethanesulfonyl fluoride. The protein concentrations of the C. albicans crude extracts were measured using known means [32]. Enzyme activity using crude extracts was commonly examined using continuous assays with a Hewlett-Packard (HP) 8452A diode array spectrometer (Palo Alto, USA). The cell lysates with $20 \mathrm{mg} / \mathrm{mL}$ crude protein were diluted $1 / 20$ with buffers, and the enzyme reaction was observed using $10 \mu \mathrm{g}$ crude protein lysates.

Glr1 activity was spectrophotometrically measured as previously described [33]. The enzyme reaction mixture consisted of $2 \mathrm{mM}$ NADPH, $20 \mathrm{mM}$ GSSH, and $10 \mu \mathrm{g}$ crude extracts in $0.2 \mathrm{M}$ potassium phosphate buffer (pH 7.4). The decrease in absorbance at $340 \mathrm{~nm}$ was monitored for $2 \mathrm{~min}$. One unit (U) of Glr1 activity was defined as the micromoles of NADPH oxidized per minute per milligram of protein, with an NADPH $\varepsilon=6.2 \mathrm{mM}^{-1} \times \mathrm{cm}^{-1}$.

The Eapx1 activity was spectrophotometrically monitored based on L-ascorbic acid oxidation using $\mathrm{H}_{2} \mathrm{O}_{2}$ at $290 \mathrm{~nm}\left(\varepsilon=2.8 \mathrm{mM}^{-1} \times \mathrm{cm}^{-1}\right)$ [34]. The enzyme activity assay mixture consisted of $0.5 \mathrm{mM} \mathrm{L}$-ascorbic acid and $0.1 \mathrm{mM} \mathrm{H}_{2} \mathrm{O}_{2}$, in $50 \mathrm{mM}$ potassium phosphate $(\mathrm{pH}$ 7) [19].

Ccp1 activity was detected using previously detailed methods [35]. To avoid overlapping of enzyme activity with that of catalase owing to competition for $\mathrm{H}_{2} \mathrm{O}_{2}$, the samples were treated with the catalase activity inhibitor $20 \mathrm{mM}$ aminotriazole prior to Ccp 1 activity determination. Ccp 1 activity was measured at $550 \mathrm{~nm}$ by observing the oxidation of dithionite-reduced cytochrome $c$. The enzyme reaction mixture consisted of $20 \mu \mathrm{M}$ reduced cytochrome $c$ in $50 \mathrm{mM}$ sodium acetate buffer (pH 6). Cytochrome $c$ reduction was observed at $550 \mathrm{~nm}$, with an extinction coefficient $(\varepsilon)$ of $27.7 \mathrm{mM}^{-1} \mathrm{~cm}^{-1} \mathrm{mM}^{-1}$. The enzyme activity reaction was performed by the addition of $0.1 \mathrm{mM} \mathrm{H}_{2} \mathrm{O}_{2}$. Ccpl activity was tested at $550 \mathrm{~nm}$ by observing the oxidation of ferrocytochrome $c\left(\Delta_{\varepsilon 550}=\right.$ $\left.19.6 \mathrm{mM}^{-1} \mathrm{~cm}^{-1}\right)$, as proposed previously [36]. One unit (U) is defined as the amount of enzyme required to oxidize $1 \mu \mathrm{mol}$ ferrocytochrome $c / \mathrm{min}$.

Total peroxidase activity was spectrophotometrically measured by examining the oxidation of $o$-dianisidine dihydrochloride (Sigma-Aldrich) at $460 \mathrm{~nm}$. The enzyme reaction mixture consisted of $0.3 \mathrm{mg} o$-dianisidine dihydrochloride/ml, $18 \mathrm{mM} \mathrm{H}_{2} \mathrm{O}_{2}$, and an appropriate amount of protein extract in $10 \mathrm{mM}$ potassium phosphate buffer ( $\mathrm{pH} 7$ ). One unit (U) was equivalent to an increase of $11.3 \mathrm{units} / \mathrm{min}$ in $\mathrm{A}_{460}$, with an absorption coefficient of $11.3 \mathrm{M}^{-1} \mathrm{~cm}^{-1}$ for $o$-dianisidine [37].

The enzyme activities of $\mathrm{Cu}-\mathrm{Zn}$ Sod (Sod1) and Mn Sod (Sod2) were measured based on the inhibitory activities of xanthine oxidase-induced catalysis of xanthine to produce superoxide anion-free radicals. Superoxide radicals oxidize hydroxylamine to produce nitrite, which reacts with a developer to produce a purple color. The $\mathrm{Cu}-\mathrm{Zn}$ Sod and Mn Sod activity assay kit (Nanjing Jiancheng Bioengineering Research Institute) was used to observe Sod 1 and Sod 2 activities, respectively. One unit (U) of Sod activity is commonly defined as the amount of Sod required to inhibit xanthine oxidation by $50 \%$ of proteins $(\mathrm{U} / \mathrm{mg})$.

The enzyme activity of MG oxidation and MG reduction by Mgd and MG reductase (Mgr) was measured in cell crude extracts based on the ability of the enzyme to catalyze the oxidation of $\mathrm{MG}$ in the presence of $\mathrm{NAD}^{+}$and the reduction of $\mathrm{MG}$ in the presence of $\mathrm{NADH}$ [12]. The rate of $\mathrm{MG}$ oxidation and reduction was determined by an increase and decrease in absorbance at $336 \mathrm{~nm}$ using an $\mathrm{NAD}(\mathrm{H}) \varepsilon=6.22 \mathrm{mM}^{-1} \times \mathrm{cm}^{-1}$ and was expressed as the 
nanomoles ( $\mathrm{nmol}$ ) of NAD reduced and NADH oxidized $\left(\mathrm{nmol} \cdot \mathrm{min}^{-1} \cdot \mathrm{mg} \mathrm{protein}^{-1}\right)$. The MG-oxidizing reaction mixture commonly consisted of $2 \mathrm{mM} \mathrm{MG}$ and $1 \mathrm{mM} \mathrm{NAD}^{+}$in $50 \mathrm{mM}^{-1}$ Tris-HCl buffer (pH 8.2) for MG oxidation; $2 \mathrm{mM} \mathrm{MG}$ and $1 \mathrm{mM}$ NADH in $50 \mathrm{mM}$ potassium phosphate buffer ( $\mathrm{pH}$ 6.5) were used to observe MG reduction.

\section{Real-Time RT-PCR}

Real-time PCR was performed using the SYBR Premix Ex TaqTM (TaKaRa) on Applied Biosystems 7300 RealTime PCR systems. Total RNA extraction was performed using a beadbeated cell lysate with an RNAiso Plus (TaKaRa) Reagent; $5 \mu \mathrm{g}$ of RNA was reverse-transcribed into cDNA using the SuperScript III Reverse Transcriptase Kit (Promega). The expression level of the target genes was normalized to that of ACT1. All primers used for the assay are indicated in Table 1.

\section{Statistical Analysis}

Data are presented as the means \pm standard deviation $(\mathrm{Sd})$. The statistical significance of the differences was evaluated using the Student's $t$-test and Microsoft Office Excel (2015). For all comparisons, ${ }^{*} p<0.05,{ }^{* *} p<0.01$, and ${ }^{* * *} p<0.001$ were considered statistically significant.

\section{Results}

\section{GSH-Deprived States in $\Delta m g d 1 / \Delta a d h 1 / \Delta g c s 1$}

Previously, near-normal cell growth of YB203 ( $\Delta g c s 1)$ and $\Delta g c s A$, by $1 \mathrm{mM}$ GSH supplementation, was observed in C. albicans and D. discoideum, respectively [38,39]. Based on this finding, to assess the effect of GSH depletion on cell viability of the triple disruptant MK803 $(\Delta m g d 1 / \Delta a d h 1 / \Delta g c s 1)$ during cell proliferation, we tested the minimal amount of exogenous GSH required for yeast growth. This was observable via the rate of exogenous GSH uptake to YB203 ( $\triangle g c s 1)$ (Fig. 1A). When considering intracellular GSH content in all disruptants by GSH uptake (Fig. 1B), it was seen that YB203 ( $\Delta g c s 1)$ did not grow below $0.05 \mathrm{mM}$ of GSH supplementation. Based on the GSH content of the wild-type cells (approximately $60.48 \mu \mathrm{mol}$ per g wet weight cells) [12], GSH uptake levels required for the cell viability of MK803 $(\Delta m g d 1 / \Delta a d h 1 / \Delta g c s 1)$ was revealed to be $0.05-0.1 \mathrm{mM}$ of GSH supplementation in the case of the late exponential growth phase $(24 \mathrm{~h})$. These values corresponded to the amount of GSH per gram wet weight cells at $24 \mathrm{~h}$. This result agreed with our previous findings of a critical threshold at the late exponential growth phase in the case of the wild-type and YB203 ( $\Delta g c s 1)$ [12]. Experiments under the control of GSH supplementation revealed extremely low GSH uptake in YB203 ( $\Delta g c s 1)$ (Fig. 1). This was very similar to results reported in prior studies conducted using GCS disruptant in other eukaryotic microorganisms, including S. cerevisiae $\Delta g s h 1$ [40] and D. dictyostelium $\Delta g c s A$ [41]. All of the GSH-depleted disruptants exhibited severe GSH-deficient states. Particularly, the GSH content in all disruptants transferred from $0.1 \mathrm{mM} \mathrm{GSH}$-containing media were commonly near a below-critical threshold between 2.08 and $3.14 \mu \mathrm{mol}$. These GSH concentrations turned out to be under 0.05 and $0.1 \mathrm{mM} \mathrm{GSH}$ supplementation of GSH per gram wet weight cells at $24 \mathrm{~h}$. Thus, further experiments were performed using all disruptants transferred from 1 and $0.1 \mathrm{mM} \mathrm{GSH}$-supplemented media until the late-exponential phase at approximately $24 \mathrm{~h}$.

\section{The Decreased NADH-Linked Mgr Activity in $\triangle$ gcs1-Based Disruptants}

To assess the effect of $M G D 1$ and $A D H 1$ expression in YB203 ( $\Delta g c s 1)$ on antioxidative enzyme activities, the previously constructed $M G D 1$ and $A D H 1$ disruptants were used in this study $[11,12]$; MK603 $(\Delta m g d 1 / \Delta g c s 1)$, MK703 ( $\Delta a d h 1 / \Delta g c s 1)$, and MK803 ( $\Delta m g d 1 / \Delta a d h 1 / \Delta g c s 1)$. In GSH-depleted conditions, all mutant strains

A

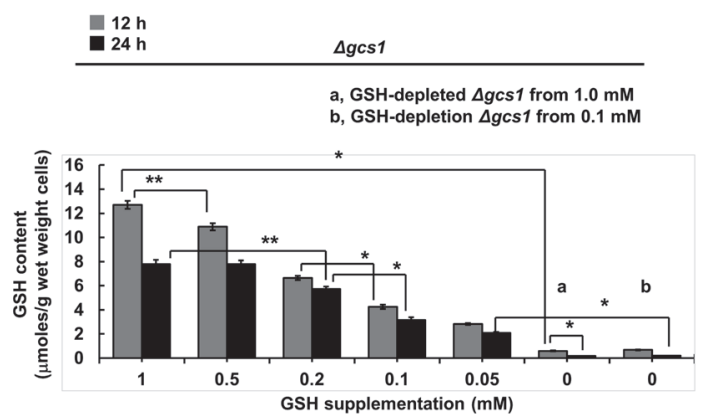

B

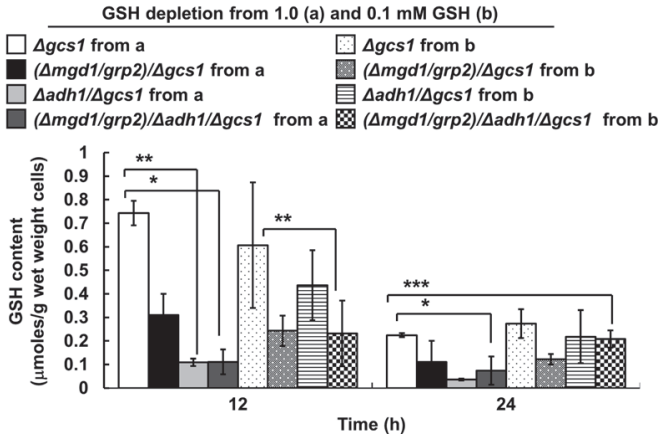

Fig. 1. The effect of GSH deprivation on MK803 ( $\Delta m g d 1 / \Delta a d h 1 / \Delta g c s 1)$. (A) Cellular GSH uptake rates in SD liquid medium. The GSH content in this strain was measured by means described in the Materials and Methods section. (B) The cellular content of GSH in w $\Delta g c s 1$-based disruptants. All Candida cells were grown on SD liquid broths for $24 \mathrm{~h}$ until the late exponential phase under the following conditions: a and b, 1 and $0.1 \mathrm{mM} \mathrm{GSH}$-supplemented $\Delta g c s 1$-based disruptants, transferred from a and $\mathrm{b}$ grown to the mid-exponential phase at $18 \mathrm{~h}$, respectively. All experiments were conducted independently in triplicate. Data are represented as the mean \pm standard deviation (Sd). Asterisks indicate statistically significant values $\left({ }^{*} p<0.05,{ }^{* *} p<0.01\right.$, and $\left.{ }^{* *} p<0.001\right)$. 
A

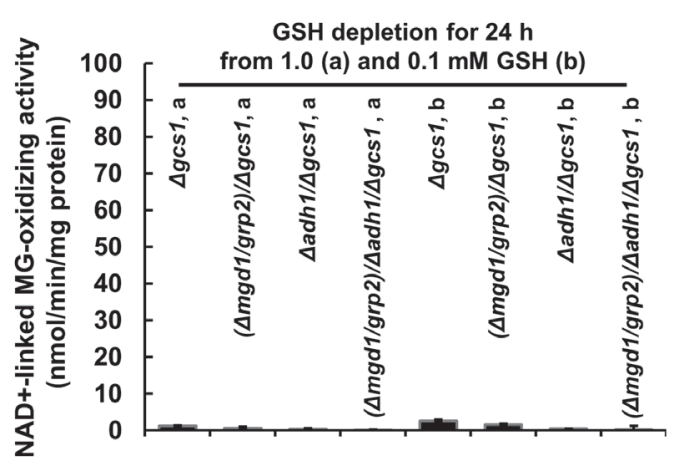

B

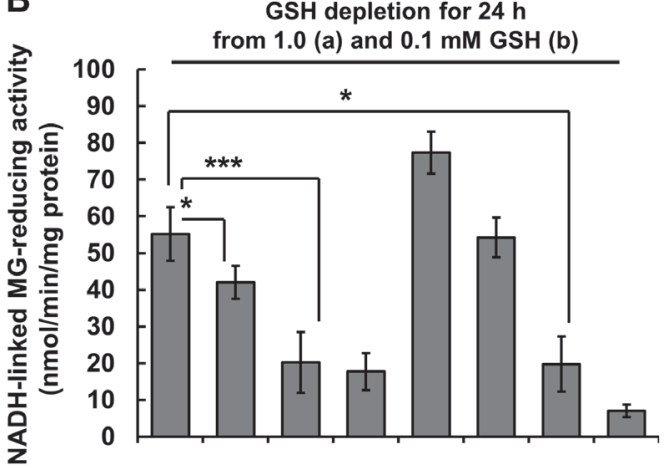

Fig. 2. The effect of both MGD1 and ADH1 gene disruption on Mgd and Mgr activities in $\Delta$ gcs1-derived MK803 ( $\Delta m g d 1 / \Delta a d h 1 / \Delta g c s 1)$. The activity of MG oxidation and reduction by (A) Mgd and (B) Mgr was observed based on the ability of the enzyme to catalyze the oxidation of $\mathrm{MG}$ in the presence of $\mathrm{NAD}^{+}$and the reduction of $\mathrm{MG}$ in the presence of $\mathrm{NADH}$, respectively. All strains grown in SD were harvested every $12 \mathrm{~h}$ to conduct biochemical experiments at both the midand the late-exponential growth phases. All experiments were conducted independently at least three times. Data are represented as the mean $\pm S d$ of three independent experiments $\left({ }^{*} p<0.05,{ }^{* *} p<0.01,{ }^{* * *} p<0.001\right)$.

showed negligibly low Mgd activities under all experimental conditions (Fig. 2A). However, compared to YB203 $(\Delta g c s 1)$, commonly decreased Mgr activity was shown in all disruptants; MK703 ( $\Delta a d h 1 / \Delta g c s 1)$ and MK803 ( $\Delta m g d 1 / \Delta a d h 1 / \Delta g c s 1)$ had a noticeably lower Mgr activity than YB203 ( $\Delta g c s 1)$ (Fig. 2B). Thus, the Mgr activity of Adh1 was thought to be the main MG-scavenging enzyme in YB204 ( $\Delta g c s 1)$-derived disruptants, including MK603 ( $\Delta m g d 1 / \Delta g c s 1$, MK703 ( $\Delta a d h 1 / \Delta g c s 1)$, and MK803 ( $\Delta m g d 1 / \Delta a d h 1 / \Delta g c s 1)$. This result suggested that MG-reducing activity is the predominant MG detoxification strategy in C. albicans.

\section{Supraphysiological MG Accumulation in $\Delta m g d 1 / \Delta a d h 1 / \Delta g c s 1$}

Quinoxaline derivatives, 2-methylquinoxaline and 2-hydroxy-3-methylquinoxaline, were quantified in all disruptants (Fig. 3). As expected, the intracellular MG content significantly increased in all of the $\Delta g c s 1$-based disruptants. However, while our previous observations suggested that Mgd1 and/or Adh1 activity deficiency accumulates MG and pyruvate without exception in MK603 ( $\Delta m g d 1 / \Delta g c s 1)$ and MK703 $(\Delta a d h 1 / \Delta g c s 1)[11,12]$, a decrease in pyruvate was seen in MK803 $(\Delta m g d 1 / \Delta a d h 1 / \Delta g c s 1)$. This result was not displayed in double genedisrupted strains, including MK603 $(\Delta m g d 1 / \Delta g c s 1)$ and MK703 ( $\Delta a d h 1 / \Delta g c s 1)$. This metabolite content change behavior did not also coincide with previous experiments using the wild type-based disruptants (MK303 ( $\Delta m g d 1)$ and MK403 ( $\triangle a d h 1)$, or Mgd1-overproducing mutants of MG and pyruvate in MK306 $\left(M G D 1^{O E}\right)$ and MK606 $\left(\left(M G D 1^{O E}\right) / \Delta g c s 1\right)[11,12]$. The decrease in pyruvate content in MK803 $(\Delta m g d 1 / \Delta g c s 1)$ was assumed to be based on the absence of both MGD1 and ADH1. This hypothesis was posited due to Mgd1 being responsible for catalyzing the reduction of pyruvate into lactate [12].
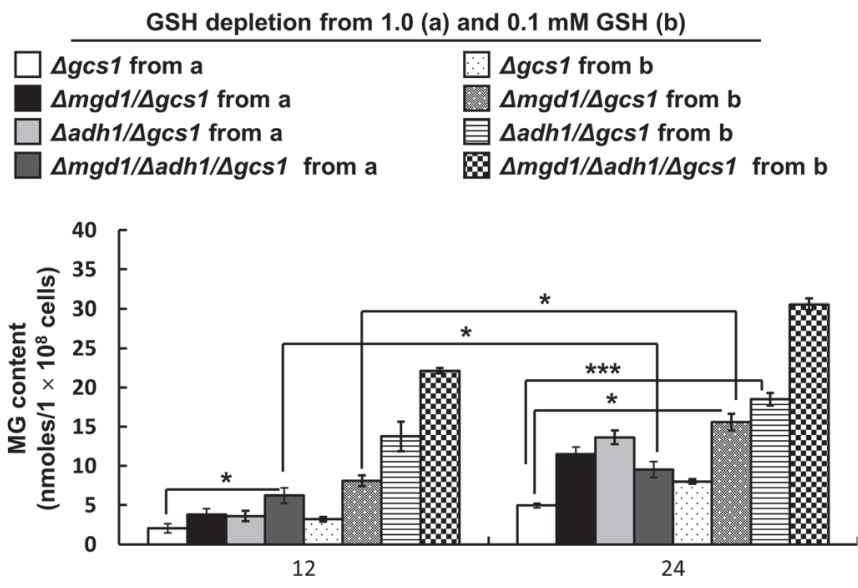

Fig. 3. The intracellular contents of MG and pyruvate in $\Delta g c s 1$-based disruptants. To monitor intracellular MG pyruvate contents, the $M G D 1$ and $A D H 1$ disruptants in $\triangle g c s 1$ were used to determine MG pyruvate content changes in SD liquid media. Exponentially growing cells at $18 \mathrm{~h}$ were transferred and regrown in minimally defined SD broth in this experiment. The values represent the averages \pm standard deviation of three independent experiments. 
GSH depletion from 1.0 (a) and $0.1 \mathrm{mM} \mathrm{GSH}$ (b)

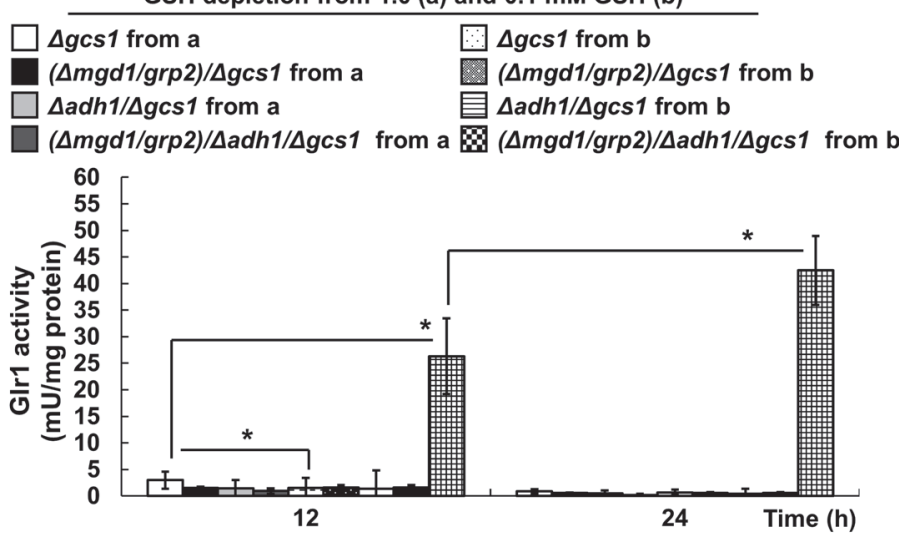

Fig. 4. The effect of both MGD1 and ADH1 gene disruption on GIr1 activity in MGD1 and/or ADH1 disruptants. Cellular Glr1 activity was measured spectrophotometrically using continuous assays. One unit (U) of the enzyme is defined as described in the Materials and Methods section. Each experimental sample was compared to wild-type SC5314. As with the other experiments, C. albicans strains were commonly grown in SD liquid media. All experiments were conducted independently at least three times. Data are represented as the mean $\pm \mathrm{Sd}$ of the experiments $\left({ }^{*} p<0.05,{ }^{* *} p<0.01\right.$, $\left.{ }^{* * *} p<0.001\right)$.

Extremely Low GIr1 Activity with ROS Content in $\Delta g c s 1$-Based Double and Triple Disruptants

Based on the extremely low GSH (Fig. 1) and supraphysiological MG levels in MK803 ( $\Delta m g d 1 / \Delta g c s 1)$ (Fig. 3), we examined Glr1 activity's association with Mgd1 and Adh1 activities (Fig. 4). All experimental groups were compared to GSH-depleted YB203 ( $\Delta g c s 1)$-derived disruptants. A negligibly low GSH content-derived Glr1 activity (Fig. 1) was seen in all disruptants. GSH-depleted MK603 ( $\Delta m g d 1 / \Delta g c s 1)$ and MK703 ( $\Delta a d h 1)$ exhibited more severe defects in the Glr1 activity than YB203 ( $\Delta g c s 1)$. The results strongly indicate that Glr1 activity is not involved the regulation of MK803 ( $\Delta m g d 1 / \Delta g c s 1)$, and other YB203 $(\Delta g c s 1)$-based disruptants, despite evident changes in MG and GSH seemingly being associated with GSH-dependent physiological states in our previous works $[11,12]$. The data also suggest Glr1 activity- and GSH-independent redox states, particularly for MK803 $(\Delta m g d 1 / \Delta g c s 1)$.

To correlate between GSH-independent redox states and ROS accumulation in these mutants, cellular $\mathrm{H}_{2} \mathrm{O}_{2}$ (Fig. 5A) and superoxide (Fig. 5B) levels were determined using dihydroethidium and $\mathrm{H}_{2}$ DCFDA, respectively. In the GSH- and Glr1 activity-independent redox states (Fig. 5), cellular ROS in MK603 ( $\Delta m g d 1 / \Delta g c s 1$ ) and MK703 ( $\triangle a d h 1 / \Delta g c s 1$ ) significantly increased proportionally to MG accumulation (Fig. 3). However, cellular $\mathrm{H}_{2} \mathrm{O}_{2}$ and superoxide in MK803 $(\Delta m g d 1 / \Delta a d h 1 / \Delta g c s 1)$ evenly decreased under all experimental conditions, especially in GSH-depleted MK803 ( $\Delta m g d 1 / \Delta a d h 1 / \Delta g c s 1)$ transferred from $0.1 \mathrm{mM} \mathrm{GSH-containing} \mathrm{SD} \mathrm{liquid} \mathrm{media} \mathrm{in} \mathrm{the}$ late exponential phase $(24 \mathrm{~h})$. The data suggest, based on the absence of enzyme activities of both Mgd1 and Adh1,

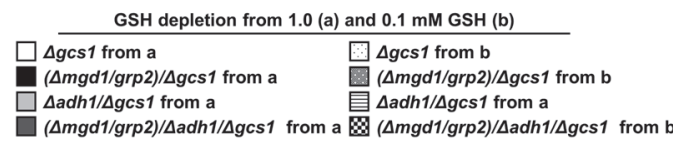

A

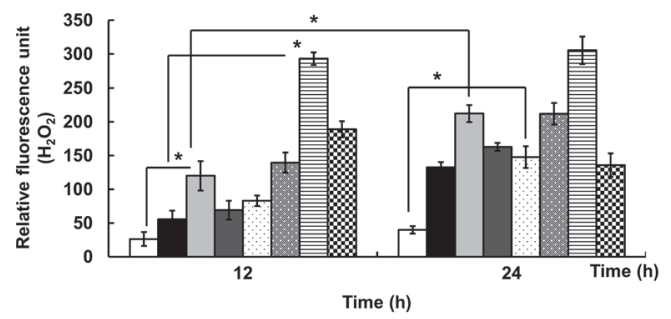

B

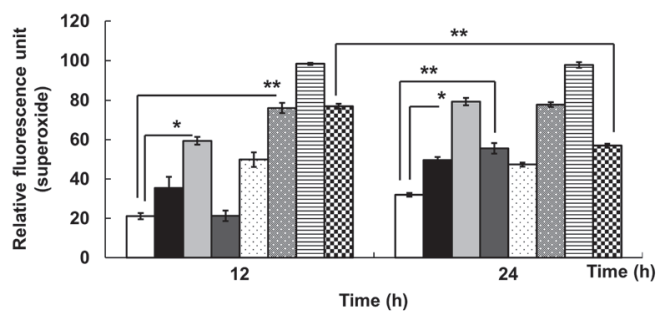

Fig. 5. Cellular content of $\mathrm{H}_{2} \mathrm{O}_{2}$ and superoxide in MGD1- and/or ADH1-deficent $\Delta$ gcs1-derived MK803

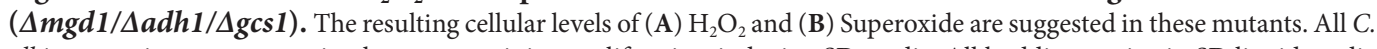
albicans strains were grown in glucose-containing proliferation-inducing SD media. All budding strains in SD liquid media were cultured and harvested every $12 \mathrm{~h}$ to measure ROS content at both the mid- and the late-exponential growth phases. Exponentially grown cells at $18 \mathrm{~h}$ were transferred and regrown in minimally defined SD broth. All biological samples were prepared as described in Materials and Methods. Data are represented as the mean \pm Sd of three independent experiments $\left({ }^{*} p<\right.$ $\left.0.05,{ }^{* *} p<0.01,{ }^{* * *} p<0.001\right)$. 
GSH depletion from $1.0(a)$ and $0.1 \mathrm{mM} \mathrm{GSH} \mathrm{(b)}$ $\triangle$ gcs1 from a $\Delta m g d 1 / \Delta g c s 1$ from a $\Delta a d h 1 / \Delta g c s 1$ from a $\Delta m g d 1 / \Delta a d h 1 / \Delta g c s 1$ from a
B

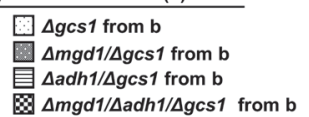

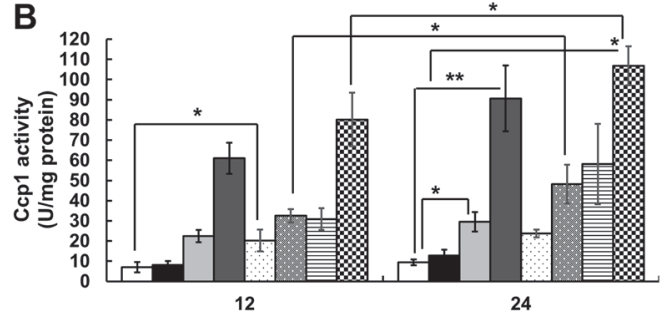

C

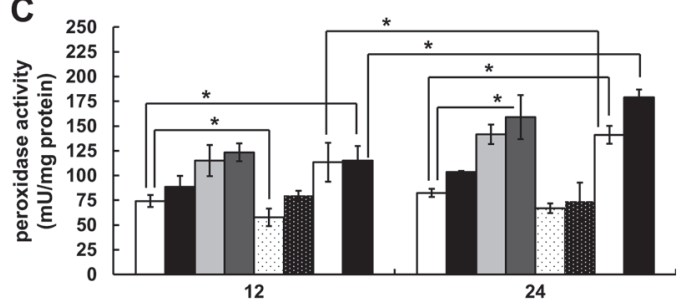

A

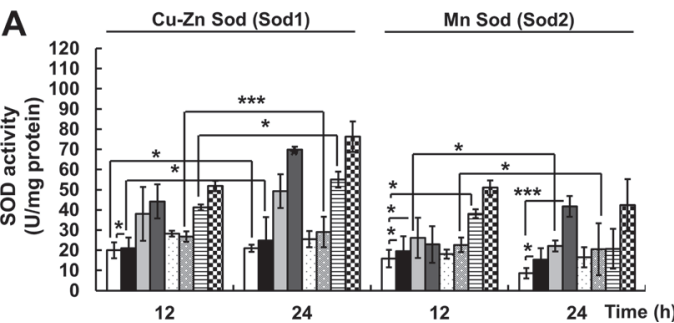

Fig. 7. The effect of GSH-independent enzyme activities on $\Delta$ gcs1-based disruptants in C. albicans. Enzyme activities of (A) Sod1 and Sod2, (B) Ccp1, and (C) total peroxidases in MK803 ( $\Delta m g d 1 / \Delta a d h 1 / \Delta g c s 1)$. Exponentially grown cells at $18 \mathrm{~h}$ were transferred and regrown in a minimally defined SD liquid medium at $28^{\circ} \mathrm{C}$. All experiments were repeated at least three times. Error bars denote $S d .{ }^{*} p<0.05,{ }^{* *} p<0.01$, and ${ }^{* *} p<0.001$, calculated using Student's $t$-test.

\section{Discussion}

The present study is based on the hypothesis that MG accumulation--through both the deprivation of MGscavenging enzymes and induced GSH depletion--alters GSH-independent antioxidative enzyme activities. The study model, using Mgd1 and Adh1 in human pathogenic C. albicans, can provide an insight into another functional role for MG scavengers through the possible involvement of other physiological events altering the regulation of their interactive partners. Mgd1 consists of 341 amino acids with a molecular mass of 37,633.69 Da (http://web.expasy.org/compute_pi/). As one subunit of a monomer, this protein is a typical aldo-keto oxidoreductase [45], similar to Gre2 encoded by S. cerevisiae YOL151w. These enzymes are commonly induced by intracellular osmotic stress [46]. To avoid misleading information, because this protein has already been annotated as Grp2 based on a domain search of the C. albicans genome database, the previously characterized Mgd protein in our study has been designated as Mgd1 [12]. Interestingly, a conserved Candida cinnamyl Adh sequence and an $\mathrm{NAD}^{+}$-binding motif have been observed in Mgd1 and Adh1 (http://www.ncbi.nlm.nih.gov/ Structure/cdd/wrpsb.cgi).

Thus, under the control of the absence of MG-consuming enzyme activities, we preferentially consider the stress-strain characteristics of $\Delta g c s 1$ in C. albicans. Fig. 1 shows non-viable C. albicans $\Delta g c s 1$ during GSH starvation. These data suggest a key role for GSH as a redox buffer in cells. To assess the effect of GSH depletion on cellular redox state via antioxidative enzyme activities in the absence of MG scavengers in this strain, nearly nonviable $\Delta g c s 1$ supplemented with $0.05 \mathrm{mM} \mathrm{GSH}$ was excluded from this study. This is due to there being extremely low cell numbers by cell lysis, especially in MK803 ( $\Delta m g d 1 / \Delta a d h 1 / \Delta g c s 1)$. Particularly, GSH-depleted $\Delta g c s 1$ transferred from 1 and $0.1 \mathrm{mM} \mathrm{GSH}$-containing SD liquid medium was cultured for heterozygous $\mathrm{Ura}^{+}$mutants for comparisons between antioxidative enzymes' physiological and metabolic changes. However, we repeatedly failed to collect a sufficient number of cells from GSH-depleted triple disruptant MK803 ( $\Delta m g d 1 / \Delta a d h 1 / \Delta g c s 1)$ transferred from $0.1 \mathrm{mM} \mathrm{GSH}$-containing medium (data not shown). The low cell numbers meant that bioassays for MG and pyruvate content could not be easily performed. Thus, $\mathrm{Ura}^{+}$heterozygous MK803 $(\Delta m g d 1 / \Delta a d h 1 /$ $\Delta g c s 1)$ had to be grown in a 15 -fold higher volume of SD broth than the other mutants. Importantly, in the case of GSH uptake below $1 \mathrm{mM} \mathrm{GSH}$, supplementation in this study should be assumed to be three-fold greater than the GSH synthesis rate previously used for $1 \mathrm{mM}$ amino acids against oxidative injury in isolated kidney cells [47]. This step was essential for observable GSH-depleted states in all disruptants with GSH-auxotrophic- and MG accumulation-characteristics, and because the intention was to convincingly provide data for GSH-independent antioxidative enzyme activities between MG-accumulating strains. When considering GSH physiology from $C$. albicans $\Delta g c s 1$, GSH-auxotrophic characteristics have been noted in other eukaryotic microorganisms. These mutants essentially require exogenous GSH for cell proliferation $[48,49]$. C. albicans $\Delta g c s 1$ displays complete GSH auxotrophy, with typical markers of apoptosis [21] and with stimulation of Adh1 activity [11]. Even in rich media, $\Delta g c s 1$, with its GSH-auxotrophic nature, is seemingly more susceptible to certain types of a-ketoaldehydes (i.e., glyoxal, MG, phenylglyoxal) and $\mathrm{H}_{2} \mathrm{O}_{2}$ than to reference strains [12]. These previous reports concur with our previous findings that demonstrated MG production by GSH deprivation and/or exogenous glucose treatment in the growth media resulted in growth defects with G1 phase-specific cell-cycle arrest in D. dictyostelium alrA and ornithine decarboxylase disruptants [50,51]. Because the main experimental materials were constructed based on $\Delta g c s 1$ to accumulate cellular MG and pyruvate, this study excluded GSH-supplemented $\Delta g c s 1$ to emphasize the

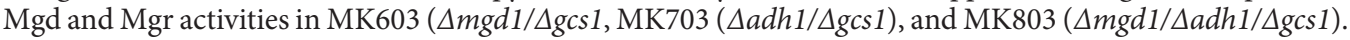


Our previous findings modeled in $\Delta g c s 1$ saw significantly enhanced Adh1 activity, catalyzing the oxidation of MG to pyruvate in GSH-depleted states [11]. Similarly, there is some evidence for the conversion of MG to pyruvate through $\mathrm{NAD}^{+}$-linked MG-oxidizing activities in $\Delta g c s 1[11,12]$, which is contrary our hypothesis for predominant MG-reducing enzyme activities for Mgd1 and Adh1. However, this behavior was seen as similar to that of high Mgr activity in cell crude extracts, and was in sharp contrast with Mgd activity in EAPX1 and CCP1 double disruptants [20]. Moreover, the results seen in Fig. 2 are thought to be partially due to Mgd1 activity being responsible for the catalysis of the reduction of pyruvate into lactate [12]. Our data indicate that Mgd activity is much lower than natural Mgr properties in yeast. Data seen in Fig. 2 thus supports findings in previous reports that Mgd activity, in many gram-positive and gram-negative bacteria, does not seem to be required for cell physiology, while Mgr activity is [52]. Interestingly, Mgr activity in S. cerevisiae seems to have a similar profile as that seen in wild-type and GSH-supplemented $\Delta g c s 1$ in C. albicans [52].

Fig. 3 illustrates a remarkable decrease in the pyruvate content of MK803 $(\Delta m g d 1 / \Delta g c s 1)$ when compared to pyruvate accumulation in MK603 $(\Delta m g d 1 / \Delta g c s 1)$ and MK703 $(\Delta a d h 1 / \Delta g c s 1)$. MK603 $(\Delta m g d 1 / \Delta g c s 1)$ and MK703 ( $\Delta a d h 1 / \Delta g c s 1)$ commonly experienced cellular accumulation of MG and pyruvate. This result is in agreement with our previous works indicating that increases in pyruvate in YM203 ( $\Delta g c s 1)$ and its-derived MG scavengers' disruptants results from GSH depletion in $\Delta g c s 1$. These data also correspond with a previous finding that the human neuroblastoma cell line SH-SY5Y, treated with a non-lethal dose of exogenous MG, accumulates both lactate and pyruvate owing to a limitation of intracellular utilization via the TCA cycle [53]. However, the previous and present results concerning pyruvate accumulation, do not fully correspond with our previous works, because $\mathrm{pH}$-dependent $\mathrm{Mgd} 1$ activity favors $\mathrm{NADH}$ oxidation at near-physiological $\mathrm{pH}$, ranging from 5.5 to 7.5, as against $\mathrm{NAD}^{+}$reduction at a $\mathrm{pH}$ of greater than 8 [12]. In addition, the Mgd1 activity at a near-neutral $\mathrm{pH}$ in its overproducing strains, including in MK306 $\left(M G D 1^{O E}\right)$ and MK606 $\left(\left(M G D 1^{O E}\right) / \Delta g c s 1\right)$, also appears to preferentially catalyze MG reduction to acetol rather than oxidation to pyruvate [12], because C. albicans cells normally grow in acidic environments and laboratory growth media, such as seen in the minimally defined SD used in the current study, having a pH range of 5.5-6 [54]. Thus, in the case of the reduction activity of Mgd1 and Adh1 in nature, the increase in the enzyme activities of these MG scavengers seems to be accompanied by a decrease in $\mathrm{pH}$ during growth. Meanwhile, an increase in $\mathrm{pH}$ of the culture medium is required for $\mathrm{NAD}^{+}$-linked Mgd1 and Adh1 activity. Nevertheless, as a piece of convincing evidence of the predominant reduction activity of Mgd1 and Adh1, a previous study suggested loss of GSH leading to an intracellular pH decrease was due to a reversible impairment of the $\mathrm{Na}^{+} / \mathrm{H}^{+}$antiporter; the main system for the maintenance of $\mathrm{pH}$ during the replication of the Sendai virus in Madin-Darby canine kidney cells [55]. Importantly, when looking at MG reduction activity in crude extracts (Fig. 2), the inducible Mgd1 and Adh1 activities seem to switch their catalytic activities as driven by changes in cellular GSH, MG, NAD $/ \mathrm{NADH}$ ratios resulting from the natural characteristics of our mutants. Also, other possible relevant metabolites, presumably dependent on the redox state and intra- and extracellular $\mathrm{pH}$ changes during cell growth, are hypothesized to be involved in MG metabolism. Thus, the decrease in pyruvate in MK803 ( $\Delta m g d 1 / \Delta g c s 1)$ is thought to predominantly come from the absence of both genes MGD1 and ADH1.

The negligibly low GSH content (Fig. 1), and thus Glr1 activity (Fig. 4), mean GSH-independent redox control by the disruptants lacking $M G D 1$ and $A D H 1$. This result can be supported by observable decreases in GSH and Glr1 activity in monoterpene phenol-treated C. albicans [56]. Considering the low GSH uptake rate in $\Delta g c s 1$ (Fig. 1), we expected GLR1 expression enhancement to complement cellular GSH in the $\Delta g c s 1$-based disruptants in this study. However, our data regarding cellular GSH content and Glr1 activity in all disruptants (Figs. 1 and 4) contrast with notable increases seen in Glr1 activity-triggered oxidative-stress defense signaling in cytochrome $c$ peroxidase $(C C P)$ mutants in $S$. cerevisiae, including ccp1 1 and $c c p 1 \Delta$-ccp1W191F, with increased $\mathrm{H}_{2} \mathrm{O}_{2}$ resistance [57].

We have previously reported on ROS-triggered antioxidative defense enzymes, including Sod1, Sod2, KatG, Eapx1, and Ccp1 [20,58], along with antioxidative activities of Mgd1 and Adh1 [11, 12]. These antioxidative enzymes, except for the manganese-containing Sod2 disruptant $\operatorname{sod} 2 / \operatorname{sod} 2$ which does not show virulent characteristics, are commonly related to virulence and hyphal formation in C. albicans [59]. This latter report suggests that the pathophysiological function of Sod 1 differs from that of Sod 2 in C. albicans. However, only some antioxidative mechanisms for Sod 1 and Sod 2 have been reported on the pathogenicity of the C. albicans wild type strain SC5314 in budding and filamentous growth, not with GSH-independent $\Delta g c s 1$. As a representative example, cellular D-erythroascorbic acid generally activates cyanide-resistant respiration by the induction of alternative oxidase $(A O X)$ gene expression in wild-type cells. However, the $A O X$ gene is not known to be responsive to $\mathrm{D}$-erythroascorbic acid-biosynthesizing gene expression independently of arabinono-1,4-lactone oxidase (Alo1) [42]. Thus, D-erythroascorbic acid-mediated AOX gene expression is independent of cellular $\mathrm{H}_{2} \mathrm{O}_{2}$ content in budding and hyphal-growing C. albicans. Also, D-erythroascorbic acid oxidation is less sensitive against exogenous $\mathrm{H}_{2} \mathrm{O}_{2}$ when compared to other oxidants. Moreover, cellular D-erythroascorbic acid content does not always affect cellular GSH content in S. cerevisiae [60]. These results suggest that ascorbic acid or Derythroascorbic acid has a limited protective role against oxidative stress in yeast cells $[42,60]$. Meanwhile, $\Delta g c s 1$ -

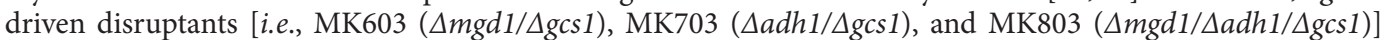
undergo severe growth defects with supraphysiological accumulation of both MG and ROS (Figs. 3-5). The behavior of these mutants illustrates another crucial role for GSH- and Glr1 activity-independent ROS detoxification by Eapx 1 and Ccp1 among antioxidative enzymes, parallel to activities of MG scavengers. GSHindependent antioxidative activities from our mutants with decreased cellular ROS in $\Delta g c s 1$-based mutant MK803 ( $\Delta m g d 1 / \Delta a d h 1 / \Delta g c s 1)$ can be also sufficiently supported by previous investigations in plants where chloroplastic peroxidases- and/or APX-deficient plants commonly lost their ASC-oxidizing activity, which 
predominantly regulates cellular $\mathrm{H}_{2} \mathrm{O}_{2}$ [61]. Meanwhile, they display severe cellular damage by $\mathrm{H}_{2} \mathrm{O}_{2}$ [62]. Also, a chloroplastic homologue of mitochondrial $A O X$ gene expression is known to be significantly induced in $A P X-$ deficient cells [44]. In our previous study, elevated endogenous ROS reciprocally increased cellular MG content [11]. These reports illustrate that cellular GSH content does not contribute to cellular stress resistance, because cellular ROS stress is thought to be readily and drastically altered by other redox buffering mechanisms in fungi [63]. Importantly, in vitro spectrophotometric observations suggest hydrogen bonded complex formation between MG and ASC [64]. Thus, this study demonstrates the predominant antioxidative properties of Eapx1 and Ccp1 through $\Delta g c s 1$-based mutant MK803 ( $\Delta m g d 1 / \Delta a d h 1 / \Delta g c s 1)$, in the absence of both GSH redox regulation and Mgd1 and Adh1 activities. Therefore, D-erythroascorbic acid-oxidizing Eapx1, Ccp1, or other peroxidases may be engaged in redox homeostasis, independently of GSH-linked redox regulation, via the enzymatic activities of MG scavengers during GSH depletion.

Further studies are needed to consider whether the parallel mechanism seen with MK803 ( $\Delta m g d 1 / \Delta a d h 1 /$ $\Delta g c s 1)$ is similar to that of Adh1 in our previously demonstrated data [12], and whether, independently of GSH and Glr1 activities in C. albicans, this accompanies the glycolytic enzymes Fba1 and Tdh3. Also, GSH-depleted MK803 ( $\Delta m g d 1 / \Delta a d h 1 / \Delta g c s 1)$ might maximize cellular MG accumulation, affecting glycolysis and mitochondrial respiration, through the loss of the multifunctional activity of MG detoxification. In addition, based on our previous work concerning Mgd-like proteins, including aldolase and hexokinase in MGD1-deficient GSHdepleted cells as compared to wild-type and GSH-supplemented strains in terms of MG detoxification, cellular MG in GSH-depleted MK803 ( $\Delta m g d 1 / \Delta a d h 1 / \Delta g c s 1)$ might well be scavenged by other types of ADH-like proteins and glycolytic enzymes.

Taken together, MGD1 and ADH1 deficiency of MK803 ( $\Delta m g d 1 / \Delta a d h 1 / \Delta g c s 1)$ regulate key antioxidative enzymes, independently of GSH biosynthesis with the aid of $A D H 1$ expression in C. albicans. Until now, there has been no experimental evidence for GSH-independent redox regulation using MG oxidoreductase mutants in GSH-depleted cells. This is a novel finding with little direct literature support. An MGD1-deficient GSH-depleted $\Delta m g d 1 / a d h 1 / \Delta g c s 1$ strain has been examined, allowing for the estimation of cellular MG and pyruvate changes associated with poor GSH-independent redox states and possible glycolytic or mitochondrial changes. This strain has provided, and continues to provide, an excellent experimental model for creating environmental conditions specific for the induction of endogenous MG or pyruvate production during glycolysis in in vitro MG synthesis studies using GSH-deprived GSH auxotrophic mutants [65, 66].

\section{Conclusions}

This study confirms that the GSH-depleted MK803 ( $\Delta m g d 1 / \Delta a d h 1 / \Delta g c s 1)$ undergoes defects in cell growth, an increase in MG production, and a decrease in cellular pyruvate, D-erythroascorbic acid, and ROS, which is in contrast to other $\triangle g c s 1$-based MGD1- and ADH1-double gene-disrupted mutants. This model shows that the MGD1- and ADH1-deficient triple gene-disrupted strains evidently undergo metabolic changes in cellular MG. These results contrast with those of our previous studies on the MGD1 single gene-disrupted strain and its overexpressing mutants, in the absence of Mgd and Glr1 activities. Of note, the inactivation of the activities of both Mgd1 and Adh1 triggers GSH-independent antioxidative enzymes, such as Eapx1 and Ccp1, in non-hyphaeinducing cells. This behavior of GSH-depleted MK803 ( $\Delta m g d 1 / \Delta a d h 1 / \Delta g c s 1)$ prominently suggests another crucial role for GSH- and Glr1 activity-independent ROS detoxification by antioxidative enzymes, especially for Eapx 1 and Ccp1 in parallel with the activities of MG scavengers. Our findings also hint at the possibility that GSHindependent defense mechanisms against oxidative stress exist in the absence of MG scavengers.

\section{Acknowledgments}

We thank W.A. Fonzi, M. Whiteway, and G.R. Fink for providing the C. albicans strains and plasmids. This study was supported by the Research Fellowship of the BK21 plus project.

\section{Conflict of Interest}

The authors have no financial conflicts of interest to declare.

\section{References}

1. Ramasamy R, Yan SF, Schmidt AM. 2012. Advanced glycation endproducts: from precursors to RAGE: round and round we go. Amino Acids 42: 1151-1161.

2. Szent-Györgyi A, Együd LG, McLaughlin JA. 1967. Keto-aldehydes and cell division. Science 155: 539-541.

3. Lee C, Yim MB, Chock PB, Yim H-S, Kang S-O. 1998. Oxidation-reduction properties of methylglyoxal-modified protein in relation to free radical generation. J. Biol. Chem. 273:25272-25278.

4. Szent-Györgyi A, McLaughlin JA. 1975. Interaction of glyoxal and methylglyoxal with biogenic amines. Proc. Natl. Acad. Sci. USA 72: $1610-1611$

5. Yim H-S, Kang S-O, Hah Y-C, Chock PB, Yim MB. 1995. Free radicals generated during the glycation reaction of amino acids by methylglyoxal. A model study of protein-cross-linked free radicals. J. Biol. Chem. 270: 28228-28233.

6. Song F, Schmidt AM. 2012. Glycation and insulin resistance: novel mechanisms and unique targets? Arterioscler. Thromb. Vasc. Biol. 32: $1760-1765$.

7. Kang Y, Edwards LG, Thornalley PJ. 1996. Effect of methylglyoxal on human leukaemia 60 cell growth: modification of DNA G1 growth arrest and induction of apoptosis. Leuk. Res. 20: 397-405.

8. Takatsume Y, Izawa S, Inoue Y. 2006. Methylglyoxal as a signal initiator for activation of the stress-activated protein kinase cascade in the fission yeast Schizosaccharomyces pombe. J. Biol. Chem. 281: 9086-9092. 
9. Choi C-H, Park S-J, Jeong S-Y, Yim H-S, Kang S-O. 2008. Methylglyoxal accumulation by glutathione depletion leads to cell cycle arrest in Dictyostelium. Mol. Microbiol. 70: 1293-1304.

10. Vander Jagt DL, Hunsaker LA. 2003. Methylglyoxal metabolism and diabetic complications: roles of aldose reductase, glyoxalase-I, betaine aldehyde dehydrogenase and 2-oxoaldehyde dehydrogenase. Chem. Biol. Interact. 143-144: 341-351.

11. Kwak M-K, Ku M, Kang S-O. 2014. NAD ${ }^{+}$-linked alcohol dehydrogenase 1 regulates methylglyoxal concentration in Candida albicans. FEBS Lett. 588: 1144-1153.

12. Kwak M-K, Ku M, Kang S-O. 2018. Inducible NAD (H)-linked methylglyoxal oxidoreductase regulates cellular methylglyoxal and pyruvate through enhanced activities of alcohol dehydrogenase and methylglyoxal-oxidizing enzymes in glutathione-depleted Candida albicans. Biochim. Biophys. Acta 1862: 18-39.

13. Aguirre J, Rios-Momberg M, Hewitt D, Hansberg W. 2005. Reactive oxygen species and development in microbial eukaryotes. Trends Microbiol. 13: 111-118.

14. Yu S, Qin W, Zhuang G, Zhang X, Chen G, Liu W. 2009. Monitoring oxidative stress and DNA damage induced by heavy metals in yeast expressing a redox-sensitive green fluorescent protein. Curr. Microbiol. 58: 504-510.

15. Emri T, Pócsi I, Szentirmai A. 1997. Glutathione metabolism and protection against oxidative stress caused by peroxides in Penicillium chrysogenum. Free Radic. Biol. Med. 23: 809-814.

16. Westwater J, McLaren NF, Dormer UH, Jamieson DJ. 2002. The adaptive response of Saccharomyces cerevisiae to mercury exposure. Yeast 19: 233-239.

17. Dantas Ada S, Day A, Ikeh M, Kos I, Achan B, Quinn J. 2015. Oxidative stress responses in the human fungal pathogen, Candida albicans. Biomolecules 5: 142-165.

18. Ku, M., Baek Y-U, Kwak M-K, Kang S-O. 2017. Candida albicans glutathione reductase downregulates Efg1-mediated cyclic AMP/ protein kinase A pathway and leads to defective hyphal growth and virulence upon decreased cellular methylglyoxal content accompanied by activating alcohol dehydrogenase and glycolytic enzymes. Biochim. Biophys. Acta 1861: 772-788.

19. Kwak MK, Song SH, Ku M, Kang SO. 2015. Candida albicans erythroascorbate peroxidase regulates intracellular methylglyoxal and reactive oxygen species independently of D-erythroascorbic acid. FEBS Lett. 589: 1863-1871.

20. Shin Y, Lee S, Ku M, Kwak M-K, Kang S-O. 2017. Cytochrome $c$ peroxidase regulates intracellular reactive oxygen species and methylglyoxal via enzyme activities of erythroascorbate peroxidase and glutathione-related enzymes in Candida albicans. Int. J. Biochem. Cell Biol. 92: 183-201.

21. Baek Y-U, Kim Y-R, Yim H-S, Kang S-O. 2004. Disruption of gamma-glutamylcysteine synthetase results in absolute glutathione auxotrophy and apoptosis in Candida albicans. FEBS Lett. 556: 47-52.

22. Sherman F. 2002. Getting started with yeast. Methods Enzymol. 350: 3-41.

23. Feng Q, Summers E, Guo B, Fink G. 1999. Ras signaling is required for serum-induced hyphal differentiation in Candida albicans. J. Bacteriol. 181: 6339-6346.

24. Hwang C-S, Oh J-H, Huh W-K, Yim H-S, Kang S-O. 2003. Ssn6, an important factor of morphological conversion and virulence in Candida albicans. Mol. Microbiol. 47: 1029-1043.

25. Fonzi WA, Irwin MY. 1993. Isogenic strain construction and gene mapping in Candida albicans. Genetics 134: 717-728.

26. Pailla K, Blonde-Cynober F, Aussel C, De Bandt JP, Cynober L. 2000. Branched-chain keto-acids and pyruvate in blood: measurement by HPLC with fluorimetric detection and changes in older subjects. Clin. Chem. 46: 848-853.

27. Biswas S, Ray M, Misra S, Dutta DP, Ray S. 1997. Selective inhibition of mitochondrial respiration and glycolysis in human leukaemic leucocytes by methylglyoxal. Biochem. J. 323: 343-348.

28. Huh W-K, Lee B-H, Kim S-T, Kim Y-R, Rhie G-E, Baek Y-W, et al. 1998. D-Erythroascorbic acid is an important antioxidant molecule in Saccharomyces cerevisiae. Mol. Microbiol. 30: 895-903.

29. Pogolotti ALJ, Santi DV. 1982. High-pressure liquid chromatography--ultraviolet analysis of intracellular nucleotides. Anal. Biochem. 126: 335-345.

30. Newton GL, Fahey RC. 1995. Determination of biothiols by bromobimane labeling and high-performance liquid chromatography. Methods Enzymol. 251: 148-166.

31. Benov L, Sztejnberg L, Fridovich I. 1998. Critical evaluation ofthe use of hydroethidine as a measure of superoxide anionradical. Free Radic. Biol. Med. 25: 826-831.

32. Lowry OH, Rosebrough NJ, Farr AL, Randall RJ. 1951. Protein measurement with the Folin phenol reagent. J. Biol. Chem. 193: 265275

33. Carlberg I, Mannervik B. 1985. Glutathione reductase. Methods Enzymol. 113: 484-490.

34. Nakano Y, Asada K. 1987. Purification of ascorbate peroxidase in spinach chloroplasts; its inactivation in ascorbate-depleted medium and reactivation by monodehydroascorbate radical. Plant Cell Physiol. 28: 131-140.

35. Yonetani T, Ray GS. 1966. Studies on cytochrome c peroxidase.3. Kinetics of the peroxidatic oxidation of ferrocytochrome $\mathrm{c}$ catalyzed by cytochrome c peroxidase. J. Biol. Chem. 241: 700-706.

36. Matthis AL, Erman JE. 1995. Cytochrome c peroxidase-catalyzed oxidation of yeast iso-1 ferrocytochrome c by hydrogen peroxide. Ionic strength dependence of the steady-state parameters. Biochemistry 34: 9985-9990.

37. de Mendez I, Young KRJ, Bignon J, Lambré CR. 1991. Biochemical characteristics of alveolar macrophage-specific peroxidase activities in the rat. Arch. Biochem. Biophys. 289: 319-323.

38. Park S-J, Kwak M-K, Kang S-O. 2017. Schiff bases of putrescine with methylglyoxal protect from cellular damage caused by accumulation of methylglyoxal and reactive oxygen species in Dictyostelium discoideum. Int. J. Biochem. Cell Biol. 86: 54-66.

39. Ku M, Baek Y-U, Kwak M-K, Kang S-O. 2017. Candida albicans glutathione reductase downregulates Efg1-mediated cyclic AMP/ protein kinase A pathway and leads to defective hyphal growth and virulence upon decreased cellular methylglyoxal content accompanied by activating alcohol dehydrogenase and glycolytic enzymes. Biochim. Biophys. Acta Gen. Subj. 1861: 772-788.

40. Ayer A, Tan SX, Grant CM, Meyer AJ, Dawes IW, Perrone GG. 2010. The critical role of glutathione in maintenance of the mitochondrial genome. Free Radic. Biol. Med. 49: 1956-1968.

41. Kim J-S, Seo J-H, Kang S-O. 2014. Glutathione initiates the development of Dictyostelium discoideum through the regulation of YakA. Biochim. Biophys. Acta 1843: 664-674

42. Huh W-K, Song Y-B, Lee Y-S, Ha C-W, Kim S-T, Kang S-O. 2008. D-Erythroascorbic acid activates cyanide-resistant respiration in Candida albicans. Biochem. Biophys. Res. Commun. 369: 401-406.

43. Huh W-K, Kim S-T, Kim H, Jeong G, Kang S-O. 2001. Deficiency of D-erythroascorbic acid attenuates hyphal growth and virulence of Candida albicans. Infect. Immun. 69: 3939-3946.

44. Rizhsky L, Hallak-Herr E, Van Breusegem F, Rachmilevitch S, Barr JE, Rodermel S, et al. 2002. Double antisense plants lacking ascorbate peroxidase and catalase are less sensitive to oxidative stress than single antisense plants lacking ascorbate peroxidase or catalase. Plant J. 32: 329-342.

45. Penning TM. 2015. The aldo-keto reductases (AKRs): overview. Chem. Biol. Interact. 234: 236-246.

46. Garay-Arroyo A, Covarrubias AA. 1999. Three genes whose expression is induced by stress in Saccharomyces cerevisiae. Yeast 15: 879-892. 
47. Hagen TM, Aw TY, Jones DP. 1988. Glutathione uptake and protection against oxidative injury in isolated kidney cells. Kidney Int. 34: $74-81$.

48. Izawa S, Inoue Y, Kimura A. 1995. Oxidative stress response in yeast: effect of glutathione on adaptation to hydrogen peroxide stress in Saccharomyces cerevisiae. FEBS Lett. 368: 73-76.

49. Kim B-J, Choi C-H, Lee C-H, Jeong S-Y, Kim J-S, Kim B-Y, et al. 2005. Glutathione is required for growth and prespore cell differentiation in Dictyostelium. Dev. Biol. 284: 387-398.

50. Choi C-H, Park S-J, Jeong S-Y, Yim H-S, S.-O. K. 2008. Methylglyoxal accumulation by glutathione dpletion leads to cell cycle arrest in Dictyostelium. Mol. Microbiol. 70: 1293-1304.

51. Kwak MK, Lee MH, Park SJ, Shin SM, Liu R, Kang SO. 2016. Polyamines regulate cell growth and cellular methylglyoxal in highglucose medium independently of intracellular glutathione. FEBS Lett. 590: 739-749.

52. Saikusa T, Rhee H-i, Watanabe K, Murata K, Kimura A. 1987. Metabolism of 2-oxoaldehydes in bacteria: purification and characterization of methylglyoxal reductase from Escherichia coli. Agric. Biol. Chem. 51: 1893-1899.

53. de Arriba SG, Stuchbury G, Yarin J, Burnell J, Loske C, Münch G. 2007. Methylglyoxal impairs glucose metabolism and leads to energy depletion in neuronal cells--protection by carbonyl scavengers. Neurobiol. Aging 28: 1044-1050.

54. Wu C, Amrani N, Jacobson A, Sachs MS. 2007. Translation initiation: extract systems and molecular genetics. 429: 203-225

55. Ciriolo MR, Palamara AT, Incerpi S, Lafavia E, Buè MC, De Vito P, et al. 1997. Loss of GSH, oxidative stress, and decrease of intracellular $\mathrm{pH}$ as sequential steps in viral infection. J. Biol. Chem. 272: 2700-2708.

56. Khan A, Ahmad A, Ahmad Khan L, Padoa CJ, van Vuuren S, Manzoor N. 2015. Effect of two monoterpene phenols on antioxidant defense system in Candida albicans. Microb. Pathog. 80: 50-56.

57. Jiang H, English AM. 2006. Phenotypic analysis of the ccp1Delta and ccp1Delta-ccp1W191F mutant strains of Saccharomyces cerevisiae indicates that cytochrome c peroxidase functions in oxidative-stress signaling. J. Inorg. Biochem. 100: 1996-2008.

58. Kwak M-K, Song S-H, Ku M, Kang S-O. 2015. Candida albicans erythroascorbate peroxidase regulates intracellular methylglyoxal and reactive oxygen species independently of D-erythroascorbic acid. FEBS Lett. 89: 1863-1871.

59. Hwang C-S, Baek Y-U, Yim H-S, Kang S-O. 2003. Protective roles of mitochondrial manganese-containing superoxide dismutase against various stresses in Candida albicans. Yeast 20: 929-941.

60. Spickett CM, Smirnoff N, Pitt AR. 2000. The biosynthesis of erythroascorbate in Saccharomyces cerevisiae and its role as an antioxidant. Free Radic. Biol. Med. 28: 183-192.

61. Ashraf M. 2009. Biotechnological approach of improving plant salt tolerance using antioxidants as markers. Biotechnol. Adv. 27: 84-93.

62. Kitajima S. 2008. Hydrogen peroxide-mediated inactivation of two chloroplastic peroxidases, ascorbate peroxidase and 2-cys peroxiredoxin. Photochem. Photobiol. 84: 1404-1409.

63. Pócsi I, Prade RA, Penninckx MJ. 2004. Glutathione, altruistic metabolite in fungi. Adv. Microb. Physiol. 49: 1-76.

64. Banerjee D, Koll A, Filarowski A, Bhattacharyya SP, Mukherjee S. 2004. Interaction between methyl glyoxal and ascorbic acid: experimental and theoretical aspects. Spectrochim. Acta A Mol. Biomol. Spectrosc. 60: 1523-1526.

65. Thornalley PJ, Langborg A, Minhas HS. 1999. Formation of glyoxal, methylglyoxal and 3-deoxyglucosone in the glycation of proteins by glucose. Biochem. J. 344: 109-116.

66. Thornalley PJ. 2008. Protein and nucleotide damage by glyoxal and methylglyoxal in physiological systems - role in ageing and disease. Drug Metabol. Drug Interact. 23: 125-150. 